\title{
An Optimized Overcurrent Protection Study Using Enough Number of SFCL at Optimal Points of a Distributed Real City Grid
}

\author{
Ahmet AKSOZ
}

\begin{abstract}
In this paper, a new approach to an optimized overcurrent protection in a distributed real city grid is presented. A superconducting fault current limiter (SFCL) can be used for solving overcurrent problems. The most important overcurrent problem in the grid are the short circuit currents, especially in high voltage lines. Therefore, many devices connected to the grid could be damaged. In spite of the protection advantages of the SFCLs, using them for all connection nodes of the grid is an expensive and complicated solution. If the optimal points of the grid to use the SFCL are decided, the most appropriate number of SFCL can be used. A 2.026 MW powered distributed real city grid application is realized in Sincan providence in Ankara City. Also, the distribution line is $0.4 \mathrm{kV}$ and the transmission line is $34.5 \mathrm{kV}$. Besides, the distributed grid is fed by two generators and two renewable energy sources which are a wind turbine and a solar power plant. Electricity consuming parts of the grid are greenhouses, loads and electrical transmission/distribution/customer lines. In order to analyse the grid, two options are simulated. Firstly, any resistive type superconducting fault current limiters (RSFCL) have been used for short-circuit protection. Results of the first option are not acceptable according to overcurrent standards. The second option is that RSFCLs are used at the optimal points of the grid. Optimal nodes are founded by the genetic algorithm. When the RSFCL is positioned at the determined optimal points, the fault current in some busbars has been obtained $82.78 \%$ less.
\end{abstract}

Keywords: distribution grid; fault current; smart grids; superconducting fault current limiter

\section{INTRODUCTION}

Faults in electrical grids are one of the most important problems of all power grids because grid installation and maintenance is a very costly task [1]. Continuous expansion of the electricity grid raises the problems of distribution grids. The capacity of the electricity grid is continuously increasing in order to meet the energy needs of the newly established facilities in Turkey too [2]. Electricity grids have different types of production and consumption lines. Electricity grid consists of transmission, distribution and customer lines. Increasing electricity demand will lead to the expansion of the distribution grid [3]. Overcurrent problems can be encountered in all distribution grids, especially in expanded distribution grids. The most effective way to get rid of the high energy demand is to solve the problem during electricity transmission and distribution before the fault current reaches the customer line [4].

The most common faults in power systems are shortcircuit faults and they pose a serious threat to human health, work equipment and plant continuity [5]. Short circuit analysis is used to determine short circuit faults that may occur in the current grid [6]. Analyses are important for the selection of system components [7]. Although these analyses are sufficient for the current grid or the extended grid, added high electricity consumption systems cause short circuit faults in the grid [8]. Short circuit currents must be prevented to provide overcurrent protection [9].

Power consuming systems should not send disturbing effects to the grid and the grid should be capable of feeding these systems [10]. However, more consumption than planned is frequently encountered in expanded distribution grids. Stable and reliable distribution of the grid is possible thanks to analyses performed to detect over consumption results that cause overcurrent faults. In addition, system efficiency can be increased significantly with these analyses [11].

When short circuit faults that occur or may occur in the grid are analysed, some methods that can prevent faults can be used. Commonly used methods for overcurrent protection are:

1) Using small structured grids

2) Using fast-reacting circuit breakers in case of the short circuit

3) Increasing the effectiveness of intervention by converting all grid into Smart Grid

4) Using Fault Current Limiters [12].

In recent years, many studies have been carried out on the use of Superconducting Fault Current Limiters (SFCL) which limit fault currents with superconductivity [13]. Mathematical model of the SFCL supplies a detailed analysis for the distribution grids. Using the equations of the SFCL and the power consumption of the grid, the most sensitive nodes of the grid for faults can be found. Thus, an operation of resistive superconducting fault current limiting for the protection of the consumer line devices can be realized [14]. The advantages of using SFCLs are mainly related to preventing overcurrent faults. The resistive SFCL (RSFCL) is a kind of SFCL that creates a virtual resistor and protects electrical systems connected to the nodes against unexpected non-standard high changes in grid current [15]. Transformation of the grid current and the grid voltage has been carried out between the transmission line and the customer line. Faults in the transmission line, the distribution line and the customer line can be prevented by using RSFCLs [16].

In this study, a distribution network for the real city network is modelled in detail. Fault points that frequently occur on the real grid are added and applied to the electricity transmission, distribution and customer line in the modelled grid. Thus, the effects of short circuit faults are observed without using SFCL. Then, the most suitable nodes for locating SFCL elements are found by using the genetic algorithm. When RSFCL is used, changes in short circuit faults in the grid are examined. Organization of the paper consists of 5 sections. In Section 2, short circuit calculation, the mathematical model of the RSFCL and the genetic algorithm are given. Modelling of the distributed real city grid and the RSFCL is described in Section 3. Section 4 presents the analyses results. Also, the paper is concluded in Section 5. 


\section{MATHEMATICAL MODELS OF THE SFCL AND SHORT CIRCUIT}

\subsection{Short Circuit Calculation}

It is necessary to calculate the short-circuit resistance for all equipment to be used in an electrical system. All of the coordination of protection circuits is based on short-circuit breaking capacities of the devices. $I_{\mathrm{k}}$ " is the initial short circuit current or the instantaneous short circuit current that is the first value of the short circuit current. The first continuous short-circuit current that is the instantaneous short-circuit current, shrinks with time, reaches a constant value and this current continues for a short while until the continuous short-circuit current is generated. $I_{\mathrm{a}}$ is the symmetrical tripping current and $\mathrm{Uh}$ is the operating voltage between phases.

It is assumed that all the contacts of the cutters will not open at the same time in the calculation of the shortcircuiting power. The breaker power is calculated by multiplying the breaking power calculated according to IEC by $100 \mathrm{kV}$ up to $1.5-100 \mathrm{kV}$ by Eqs. (1) to (3).

Three phases grounded or groundless short-circuit:

$$
I_{\mathrm{k}}{ }^{\prime \prime}=\frac{1.1 U_{\mathrm{h}}}{\sqrt{3}\left|Z_{1}\right|}
$$

Phase-to-phase short-circuit:

$$
I_{\mathrm{k}}{ }^{\prime}=\frac{1.1 U_{\mathrm{h}}}{\left|Z_{1}+Z_{2}\right|}
$$

One phase - ground short circuit:

$$
I_{\mathrm{k}}^{\prime \prime}=\frac{\sqrt{3}(1.1) U_{\mathrm{h}}}{\left|Z_{1}+Z_{2}+Z_{0}\right|}
$$

The coefficient 1.1 in the share of the formulas is used for maximum short-circuit current calculation. According to IEC 60909, the coefficient constant (c) shown here is 1.1 for maximum short-circuit current and 0.95 for minimum shortcircuit current. As can be understood from the coefficient of 1.1 , the short circuit current to be calculated by these formulas is the maximum short circuit current. If the fault point is at a remote location from the generator, the maximum short-circuit current will equal the continuous short-circuit current and the symmetrical trip current $\left(I_{\mathrm{k}} "=I_{\mathrm{k}}\right.$ $=I_{\mathrm{a}}$ ). If the fault point is near the generator, the maximum short-circuit current will be greater than the symmetrical cutoff current and greater than the continuous short-circuit current $\left(I_{\mathrm{k}}>>I_{\mathrm{a}}>I_{\mathrm{k}}\right)$. In the third chapter, current values are given.

\subsection{Mathematical Model of RSFCL}

The characteristic of an ideal current limiter as:

1) An ideal current limiter should have almost no effect on a system in steady-state. It must be zero impedance and thus none voltage changing.

2) It should be able to respond to repetitive failures occurring in a short time.
3) It should be able to automatically switch to a fault-free state without human intervention.

4) It should not affect voltage and power factor values.

5) It must be able to operate at the voltage level of the distribution system.

6) It should not interfere with the normal operation of the relay and power circuit breakers.

7) It should be small (ergonomic size), portable and easy to maintain [16].

A resistive type SFCL limits the fault current by switching from superconducting to resistive. This transition is spontaneous. The principle of superconducting the RSFCL is that it exhibits near-zero resistance under normal operating conditions while achieving high resistance in case of failure [17]. The Resistive Superconductor Fault Current Limiter (RSFCL) uses superconductor material as the current-carrying conductor. As the resistance increases, a voltage is formed on the superconductor and allows the current to flow through the parallel arm. The superconductor acts here as a switch operating in milliseconds [18]. The contributions of the SFCL to the grid and its mathematical expression are given below. limits:

Current density and resistivity according to temperature

$$
\rho=\left\{\begin{array}{lr}
0 & \left(J<J_{\mathrm{c}}, T<T_{\mathrm{c}}\right) \\
\rho_{\mathrm{c}}\left(J / J_{\mathrm{c}}\right)^{n-1} & \left(J>J_{\mathrm{c}}, T<T_{\mathrm{c}}\right) \\
\rho_{\text {over }}(T) & \left(T<T_{\mathrm{c}}\right)
\end{array}\right\}
$$

$\rho_{\mathrm{c}}=E_{\mathrm{c}} / J_{\mathrm{c}}$

$$
J_{\mathrm{c}}=J_{\mathrm{c} 0}\left(T_{\mathrm{c}}-T\right) /\left(T_{\mathrm{c}}-T_{\mathrm{op}}\right)
$$

The critical current density, critical temperature and critical resistivity values are given. $J_{c 0}$ is the critical current density at $350{ }^{\circ} \mathrm{C}$. $T_{\mathrm{op}}$ is the current process temperature. $n$ is the exponential coefficient. $p_{\text {over }}(T)$ is the resistivity value in the supercritical temperature range and it is expressed as follows [16].

$$
\rho_{\text {over }}(T)=\left\{\begin{array}{c}
-3.2783+0.07031 T 10^{-9} \Omega \mathrm{m} \\
\left(350{ }^{\circ} \mathrm{C}<T<453{ }^{\circ} \mathrm{C}\right) \\
-3.1737+0.06965 T 10^{-9} \Omega \mathrm{m} \\
\left(T>453^{\circ} \mathrm{C}\right)
\end{array}\right\}
$$

The connection between the electrical field $E$ and the current density $J$ is:

$$
\rho_{\text {over }} E=E_{0}\left(\frac{J}{J_{\mathrm{c}} \cdot T_{\mathrm{op}}}\right)^{n}
$$

Using the SFCL expressions, a RFSCL single-phase circuit equivalent in Fig. 1a from [2] and a Matlab model is designed in the direction of the above equations in Fig. $1 \mathrm{~b}$. 


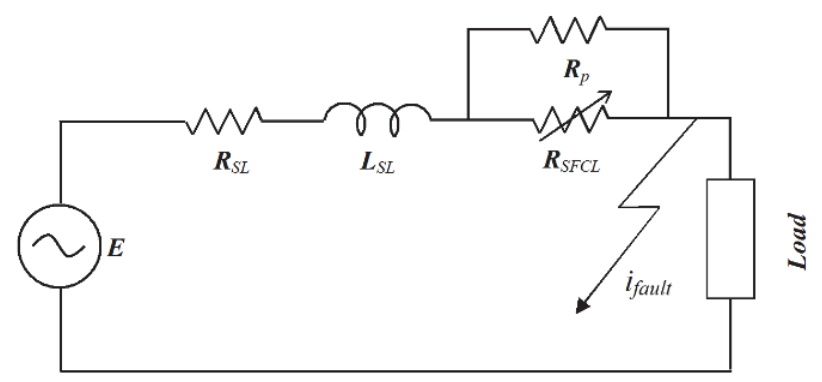

(a)
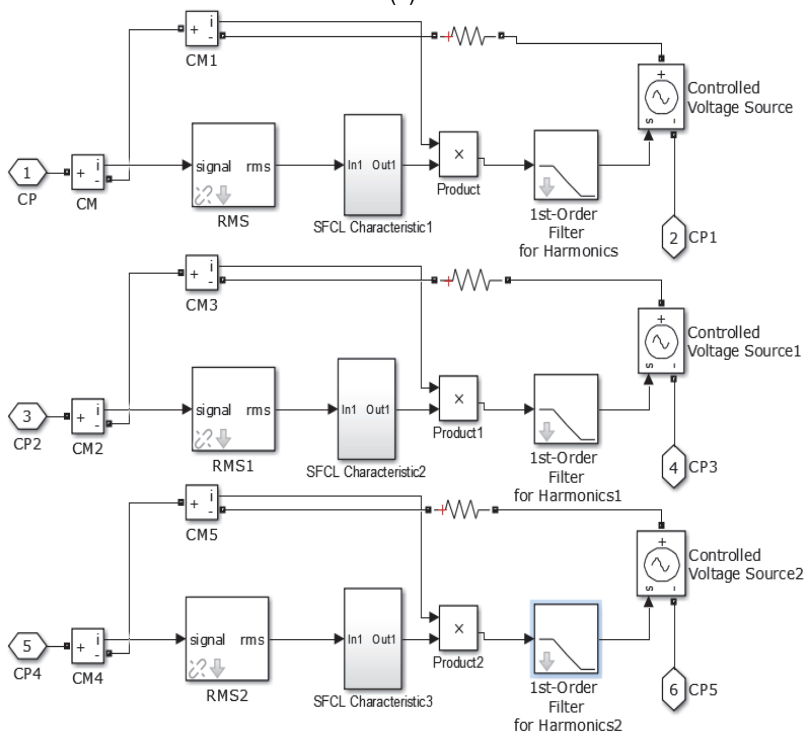

(b)

Figure 1 a) the RSFCL single-phase circuit equivalent and b) the 3 phase Matlab model of the RSFCL

When the RSFCL single-phase circuit equivalent and the 3 phase Matlab model of the RSFCL are used, the real distributed city grid can be modelled with the RSFCL.

\subsection{Multi Objective Genetic Algorithm}

The Genetic Algorithm is a bio-inspired searching and optimizing algorithm. Generally, it generates high-quality solutions. If the best results are desired, stop criteria must be well defined and the maximum iteration number must be increased [17-19]. The multi-objective genetic algorithm flow chart is shown in Fig. 2. In this study, an optimization script is coded with the MOGA to find the best points to settle the SFCL component. Algorithm in Fig. 2 was run with Matlab Simulink model. Every node at before and after other components was circulated in loops in simulation to find the best location to the SFCL using. The best nodes are given in Section 4 with the selected (the most affected) busbar simulation results.

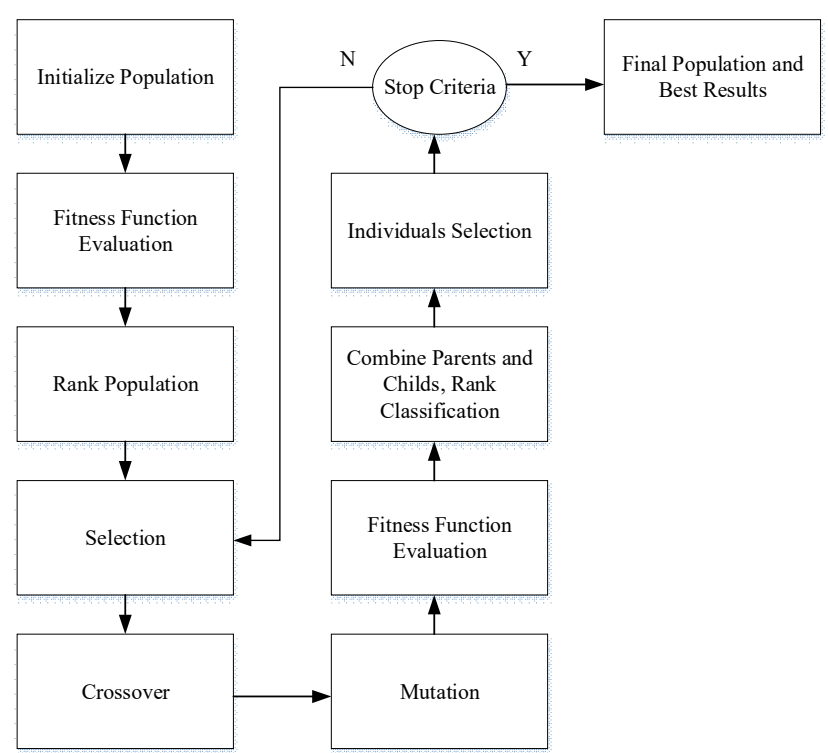

Figure 2 Multi objective genetic algorithm flow Chart [19]

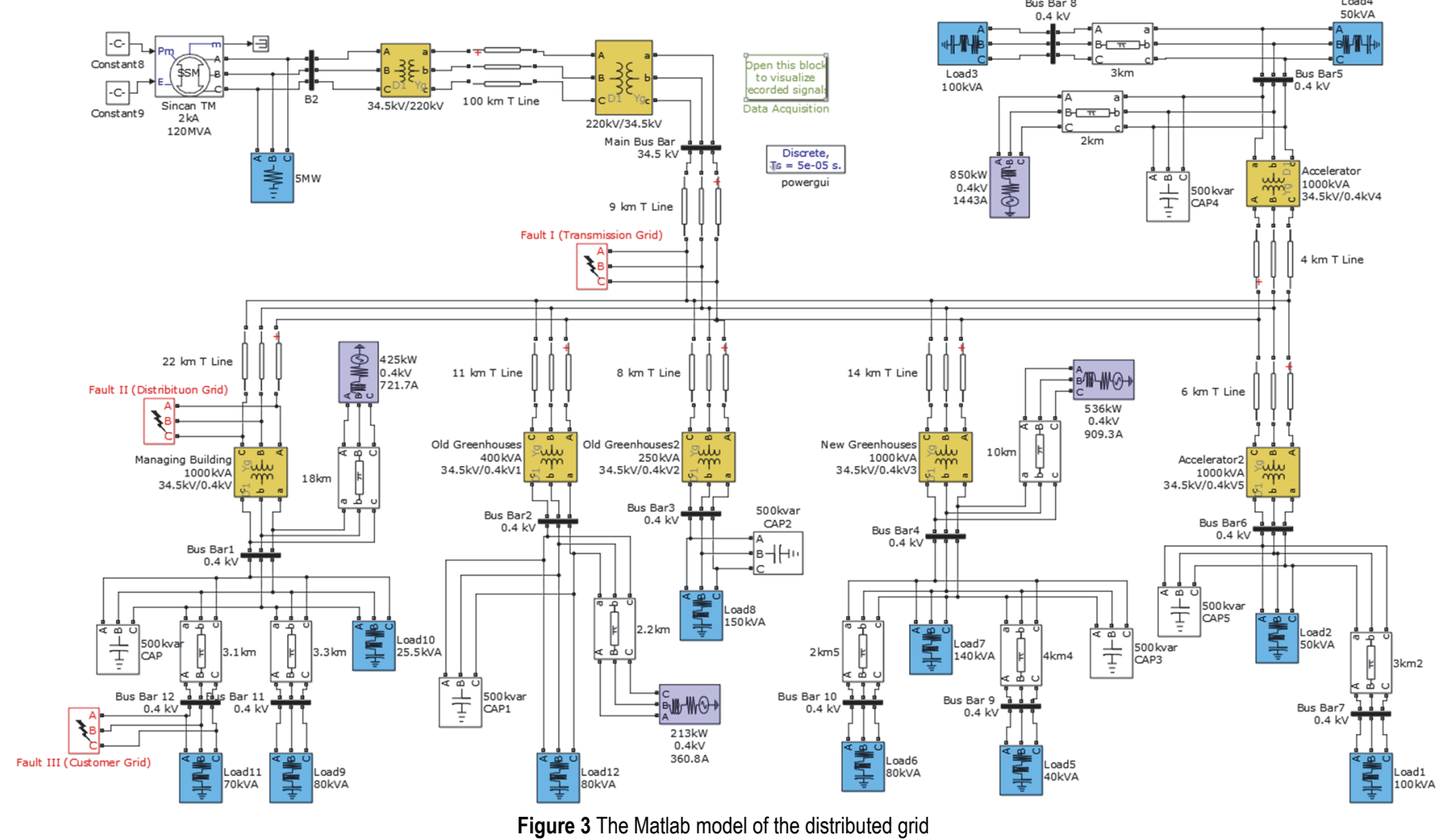




\section{MODELLING OF THE DISTRIBUTION POWER SYSTEM AND THE RSFCL}

While this system is being developed, a real distributed city grid system is used. Thus, the possible advantages can be seen more clearly. In the study, the main distribution center is fed with a nominal current of $2 \mathrm{kA}$ with a 477 MCM (Hawk) conductor line at a distance of $100 \mathrm{~km}$ with a voltage of $34.5 \mathrm{kV}$. In the block diagram for the $\mathrm{T}$ equivalent circuit, there are parameters such as frequency, resistance, inductance and capacitance components and line length. The parameter values for the energy transmission line are entered together with the respective field units. There are also four generators in the system. The total power of these generators is $2.026 \mathrm{MW}$. The distribution line is $0.4 \mathrm{kV}$ and the transmission line is 34.5 $\mathrm{kV}$. There are 6 transformer substations in the system. The distribution system is powered by 13 separate bus systems. The real city model of the distribution grid is given in Fig. 3.

Loads are important for a real analysis of the modelled system. Loading analysis of the system connected to the distribution line has been made by manual recording method and entered into the system as shown in Tab. 1.

Table 1 Loads used in the system

\begin{tabular}{|c|c|c|c|c|}
\hline Load Name & Load Type & Power / kV & Motor & Static \\
\hline Load 1 & Bulk Load & 100 & $80 \%$ & $20 \%$ \\
\hline Load 2 & Bulk Load & 50 & $49 \%$ & $51 \%$ \\
\hline Load 3 & Bulk Load & 100 & $60 \%$ & $40 \%$ \\
\hline Load 4: & Bulk Load & 50 & $40 \%$ & $60 \%$ \\
\hline Load 5 & Bulk Load & 36 & $15 \%$ & $85 \%$ \\
\hline Load 6 & Static Load & 72 & - & - \\
\hline Load 7 & Static Load & 140 & - & - \\
\hline Load 8 & Bulk Load & 132 & $18 \%$ & $82 \%$ \\
\hline Load 9 & Bulk Load & 80 & $20 \%$ & $80 \%$ \\
\hline Load 10 & Bulk Load & 25.5 & $80 \%$ & $20 \%$ \\
\hline Load 11 & Bulk Load & 70 & $38 \%$ & $62 \%$ \\
\hline Load 12 & Bulk Load & 80 & $80 \%$ & $20 \%$ \\
\hline
\end{tabular}

In the proposed system, there are 6 transformers to provide power flow between $34.5 \mathrm{kV}$ busbar and $0.4 \mathrm{kV}$ busbar. To analyse the grid accurately, the power losses of the transformers have been determined. The amounts of loss of power specified are presented in Tab. 2. Shortcircuit active power losses cause the coils to heat up. This loss is also referred to as copper losses. Short circuit reactive power losses cause leakage magnetic flux. Idle active power losses occur as a result of hysteresis and eddy currents in the transformer's core. Idle running reactive power losses provide the basis for the creation of magnetic flux.

Table 2 Power losses in transformers

\begin{tabular}{|c|c|c|}
\hline Transformer & $\begin{array}{c}\text { Lost Active Power / } \\
\mathrm{kW}\end{array}$ & $\begin{array}{c}\text { Loss Reactive Power / } \\
\mathrm{kVAR}\end{array}$ \\
\hline Managing Building & 0.4 & 2.2 \\
\hline Old Greenhouse 1 & 0.4 & 1.1 \\
\hline Old Greenhouse 2 & 1.5 & 4.6 \\
\hline New Greenhouse & 0.7 & 4.2 \\
\hline Accelerator & 0.3 & 1.6 \\
\hline Accelerator 2 & 0.3 & 1.6 \\
\hline
\end{tabular}

Short circuits in the energy transmission and distribution system are important types of faults. These failures can occur on the transmission line, the distribution line or the consumer line. In this study, the effects of three possible failures on the system are examined. Unlike other publications, failures have not been applied to the transmission line, the distribution line or the consumer separately. All faults are assumed to be at the same time. Thus, the RSFCL performance is thought to be better understood at higher error rates. Also, the effects on each busbar of each failure have been examined separately.

\section{SIMULATION RESULTS OF THE SELECTED BUSBARS IN THE REAL CITY GRID}

Various faults occur in transformers and energy transmission lines. As a result of these failures, there are short circuit, tripping and energy losses in the grid. The three-phase error blocks in Simulink are used to give failures to busbars in the modelled grid. This block feature allows declaring the times of error creation and shutdown. Here, a long-time-interval for downtime is set to 0.06 seconds. The short-circuit types that the three-phase error block generates allow the formation of 3 phase, phasephase, 2 phase-ground, phase-ground faults. The error situation that can occur in three important points is discussed in the system. First, the short-circuit condition in the energy transmission line is examined. The short circuit in the energy transmission line occurs in 0.4 seconds. The system has been exposed to failure until it recovered in 0.46 seconds. Thus, the transmission line and the effects on 13 busbars can be seen on the transmission line. Second, a short circuit in the distribution line is given. This short circuit also starts in 0.52 seconds and ends in 0.58 seconds. The third is a short circuit in the consumer line. This error occurs at 0.64 seconds and ends at 0.7 seconds. in this study, the MainBusBar, BusBar1, BusBar2, BusBar3, BusBar7 and BusBar12 from 13 busbars are investigated because the fault current problems are often encountered in these busbars according to data from electricity distribution firm. Unit of $x$-axis is second (simulation time) for Figs. 4, $5,6,7,8$ and 9 .

Fig. $4 \mathrm{a}$ shows the effects of these three faults in the main transmission line in a sequential manner. It is shown that the fault that occurred in the transmission line seriously affected the entire system. At first, it appears that the voltage has doubled due to the short circuit and the current has risen far above the nominal current. The breakdown in the distribution line is also seen to be within the cut-off limits of the current rises in the main transmission line. The transmission line can be damaged by overcurrents in the short circuit if a precise adjustment like using a RSFCL cannot be made. In the same way, the short circuit that takes place in the consumer does not have a serious effect on the transmission line. Fig. $4 \mathrm{~b}$ shows the effects on the distribution line when three failures occur in sequence. It is seen that the distribution line is severely affected again due to transmission line failure. In the same way, influence in the distribution line failure arises. In the case of a short circuit in the line of consumption, it is seen that the results of applied failures on the distribution line are at undesirable level. But it is not possible that the distribution line relays can overcome. It is also understood that the distribution line relays cannot react in the event of possible tripping with a short circuit on the consumer side. It is seen that short circuit currents continue to pass to users in the event of possible consumer-side relay failure. 

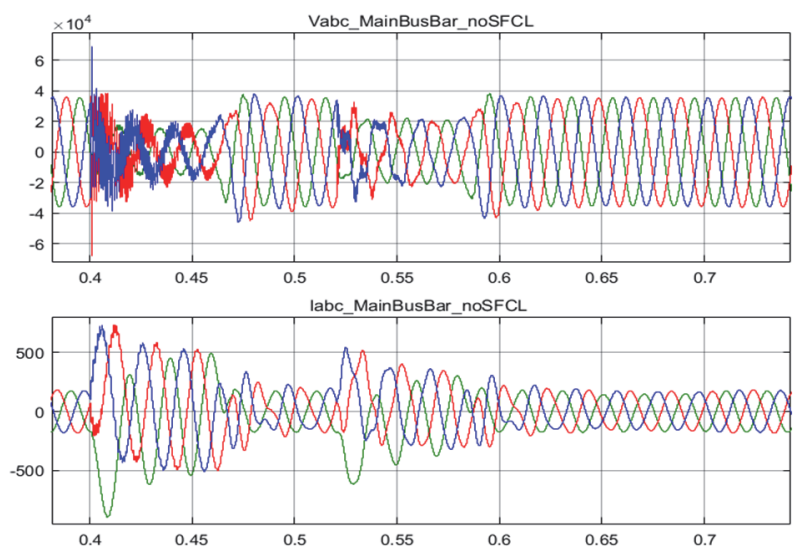

(a)
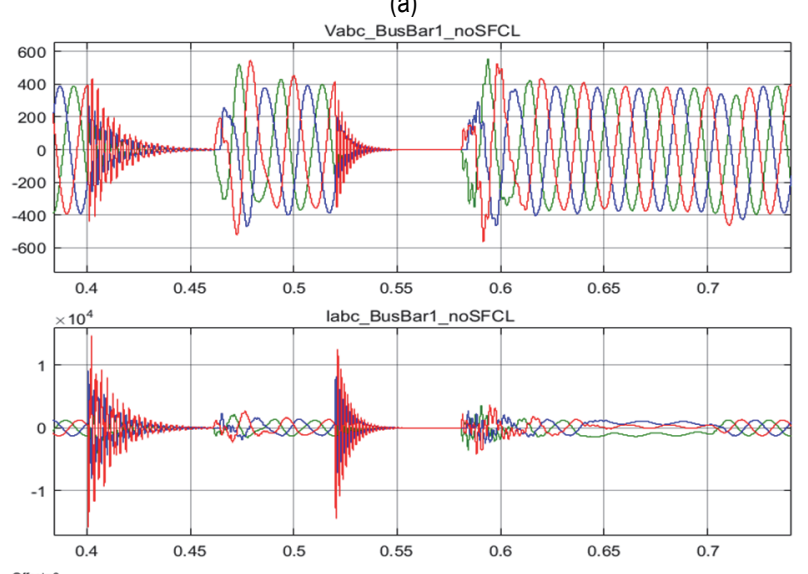

(b)

Figure 4 a) Main Bus/Power generation and transforming before using the RSFCL under 3 faults (transmission, distribution and costumer) and b) BusBar1 voltage and current before using the SFCL under 3 faults (transmission, distribution and costumer)
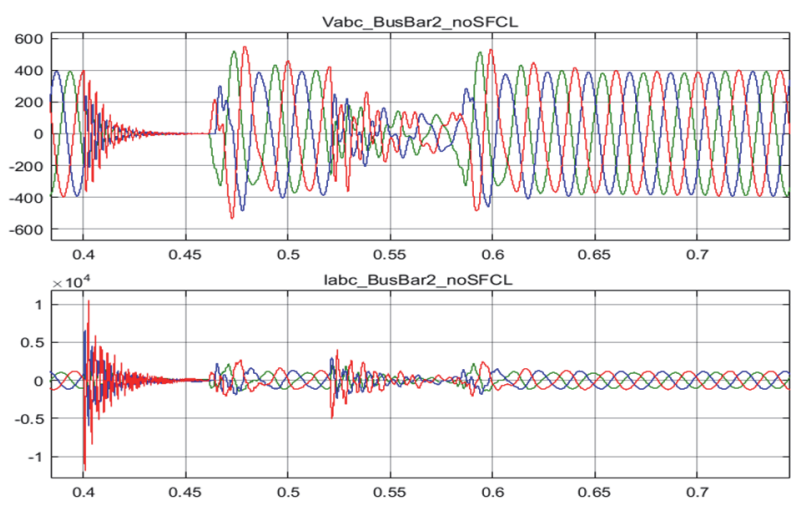

(a)
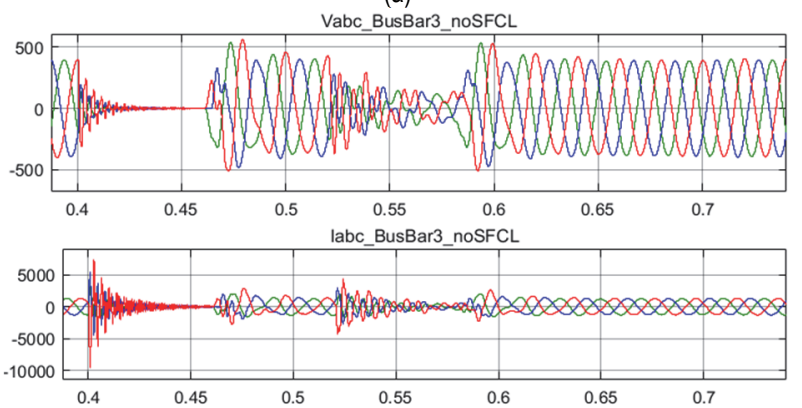

(b)

Figure 5 a) BusBar2 voltage and current before using the RSFCL under 3 faults (respectively transmission, distribution and costumer) and b) BusBar3 voltage and current before using the RSFCL under 3 faults (respectively transmission, distribution and costumer)
Also, in Fig. 5a is examined the grid voltage and grid current of the distribution line 2 which is also BusBar2 with the failures. There are less faults than in other busbars because this busbar has a generator. It generates faultless electricity and mitigates some faults. But it has been observed that the behaviour of voltage and current under these failures causes very serious changes in the energy level of the busbar. The short circuit problem should also happen in this busbar. Even though there is not a big voltage change in the connected loads, the current change because of other busbars appears to be much higher than the nominal current level. Even if the unexpected fault does not occur, the short circuit failure can be realized. The short circuit failures due to the nearest consumer have not a very significant effect on this real distributed city grid system. In Fig. 5b, the situation of the distribution line is an acceptable range under three failures in the grid. The BusBar3 is also affected less than other busbars. As can be seen in the current behaviour, the short circuit that can be realized with fault 1 is the transmission grid fault. However, the current increasing can be solved with a simple overcurrent solution. Moreover, the fault 3 in the same distribution line does not affect the BusBar3 much.
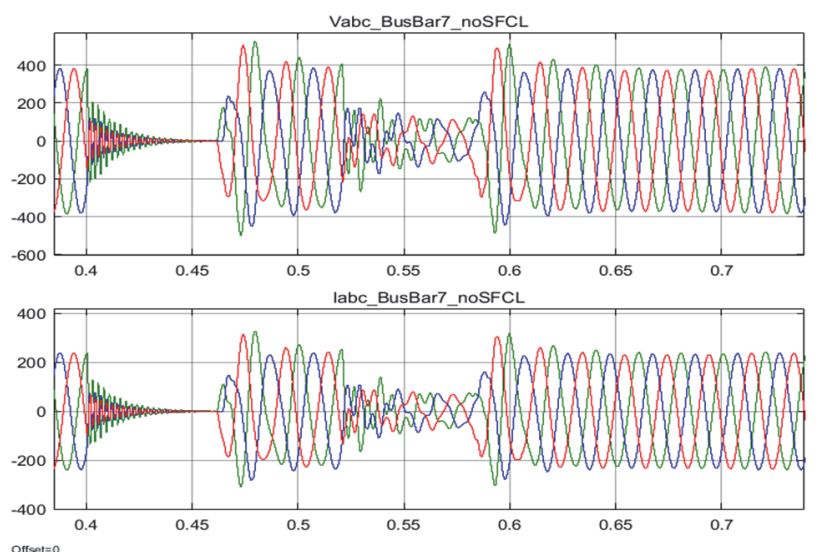

(a)
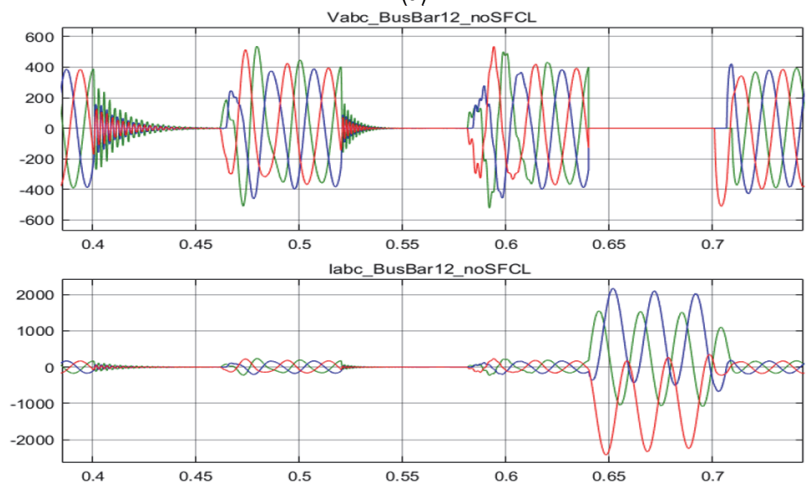

Offseat=0

(b)

Figure 6 a) BusBar7 voltage and current before using the RSFCL under 3 faults (transmission, distribution and costumer) and b) BusBar12 voltage and current before using the RSFCL under 3 faults (transmission, distribution and costumer)

In addition, Fig. $6 \mathrm{a}$ shows the situation of the distribution line in the BusBar7 which is the farthest busbar of all fault locations. The disturbing effect of the faults on the bar voltage and current are neglectable against other busbars, but a short circuit failure can occur which can be harmful for the new greenhouse costumer. Also, there is a $536 \mathrm{~kW}$ generator in the BusBar 7. Fig. 6b gives the current change and the voltage change of the consumer line where 
serious failures take place. When the obtained result is examined, it is seen that the consuming voltage and current are lower than the other busbars. But there are disturbances due to high current changing and decreasing voltage. Thus, the short circuit problem is realized in the BusBar12 too.

According to the result of the multi-objective genetic algorithm analysis in Matlab on modelled real city grid, the best connection points for the SFCL are found as the nodes where an additional power supply is a renewable energy source or a generator is connected to the system. Thus, the RSFCL is connected to the grid at connection points of the extra power sources. Then the current errors and overcurrent problem decreasing are calculated. According to the connection points of the extra power sources, RSFCLs are connected between transformers and extra power sources in the distributions grid. There are a wind renewable energy source, a solar renewable energy source and two generators that are used to support the system on lines 1, 2, 4 and 6. Both these generators and transformers must be also protected from failures. In order to achieve it, RSFCLs used in critical areas of the distribution line are the founded nodes. Thus, overcurrent and short current problems can be overcome. It has been found that faults at any point in the grid can cause a short circuit at any busbar.
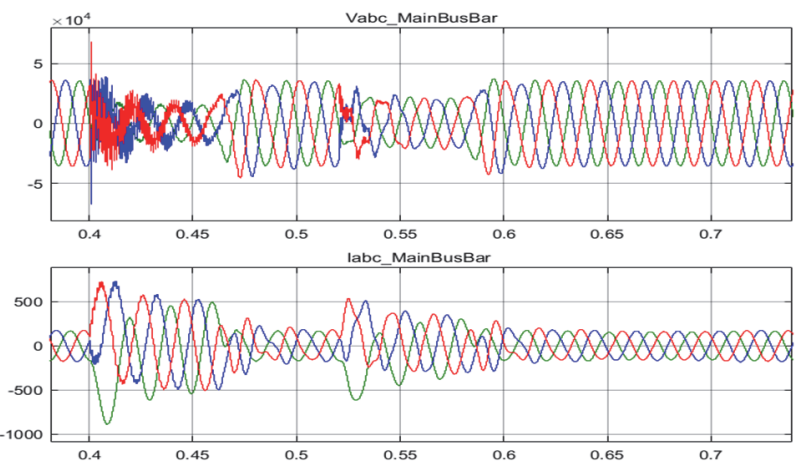

(a)
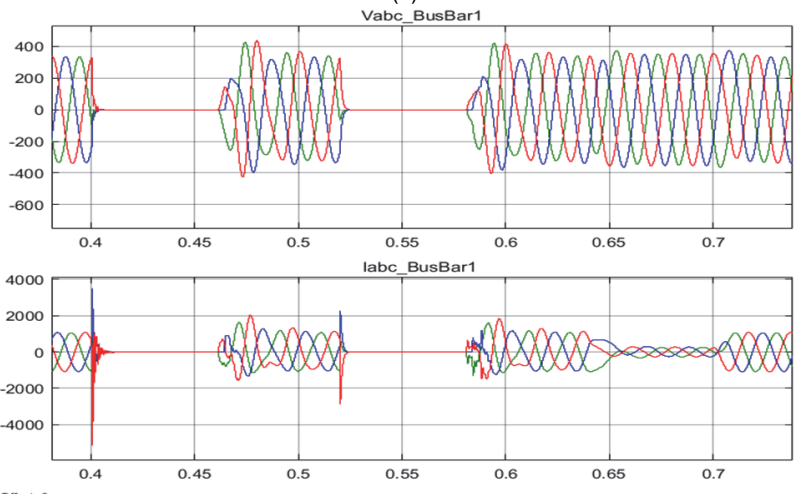

(b)

Figure 7 a) MainBusBar voltage and current after using the RSFCL under 3 faults (transmission, distribution and costumer) and b) BusBar1 voltage and current after using the RSFCL under 3 faults (transmission, distribution and customer)

After RSFCLs are connected to the system, a faultstate analysis is performed. If they are not connected to the best points of the grid, undesired faults should occur and damage to customer lines, power sources, transformers, distribution lines and transmission lines. Due to these failures, expected big problems, which are short circuit, tripping and energy losses, can cause major damages to the grid. Fault situations that may occur at three important points in the system are discussed. First, the short circuit condition in the power transmission line is examined. Short circuit in the energy transmission line is seen as system failure in 0.4-th second. However, the grid recovers it up to 0.46 -th seconds. Thus, it can be seen what problems the total effects of the first fault on the transmission line and the 13 busbars cause to distribution lines. The second fault is a fault in the short circuit condition on distribution line and its effect on the entire grid is discussed. The effect of this fault also starts at 0.52 -nd second and ends at 0.58 -th second. Third, and the most common fault is the short circuit condition on the consumer line. This is the biggest problem that must be overcome in distribution lines. This error is short-circuited in 0.64 seconds and the grid recovers in 0.7 seconds. However, these periods are enough time to overcome problems which are mainly the current-voltage ripples, short circuit, tripping and energy losses in the distributed grid.
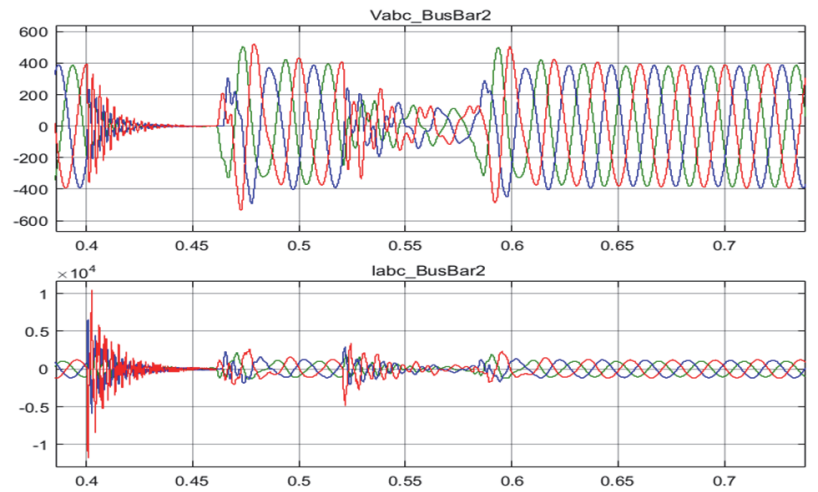

(a)
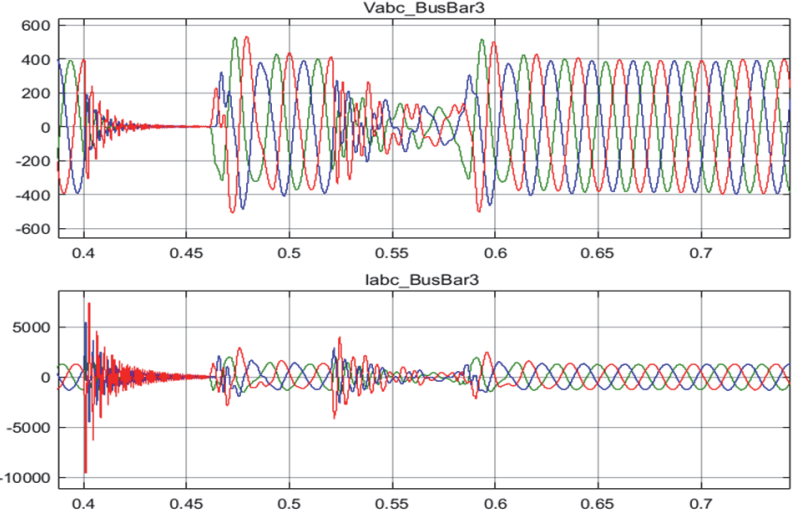

(b)

Figure 8 a) BusBar2 voltage and current after using the RSFCL under 3 faults (transmission, distribution and customer) and b) BusBar3 voltage and current after using the RSFCL under 3 faults (transmission, distribution and customer)

After the optimal points are decided, MainBusBar voltage and current after using the RSFCL under 3 faults (transmission, distribution and customer) can be seen in Fig. 7a. The short circuit problem has been eliminated. Moreover, a $4.10 \%$ improvement in the fault current is achieved. Also, BusBarl voltage and current after using the RSFCL under 3 faults (transmission, distribution and customer) can be seen in Fig. 7b. When Fig. 7 is examined, it is understood that the voltage-current ripples in the transmission line do not encounter an excessive increase except cable resistance and it is within acceptable limits under the three faults. Nonetheless, the effect of the RSFCL has been obviously seen on the MainBusBar and 
the BusBar1, the fault current problems are effectively limited. Thus, the short circuit problem has been eliminated and an improvement in the ripple of the fault current is achieved as $82 \%$.

Fig. 8a clearly shows the effect of using the RSFCL in the BusBar2 where the faults occur. The current and voltage values have not exceeded the undesired range under faults. It is seen that the SFCL does not allow overvoltage ripples and over-current ripples. As can be seen here, the connected RSFCL between the transmission line and the distribution line has an important role. As expected, a connected RSFCL to the distribution line provides very good results and provides an advantage in protecting the entire system. The short circuit problem has been eliminated. Also, 4.67\% improvement is achieved for the ripple of the fault current. Fig. 8b shows the BusBar3 voltage after using the RSFCL under 3 faults and the BusBar 3 current after using the RSFCL under 3 faults. The effect of the RSFCL in the nearest busbar to the defective consumer line can be seen. Particularly, an improvement of $4 \%$ change in fault current has been obtained thanks to the RSFCL for the short circuit in the distribution line and in the transmission line.

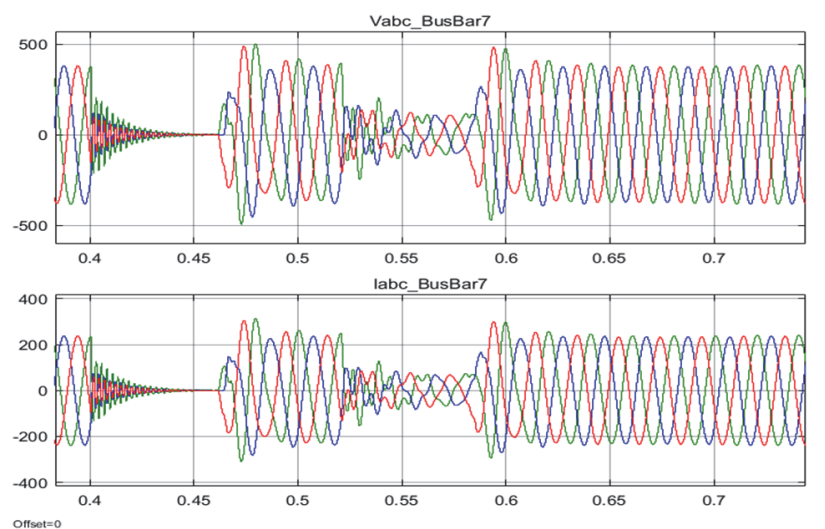

(a)
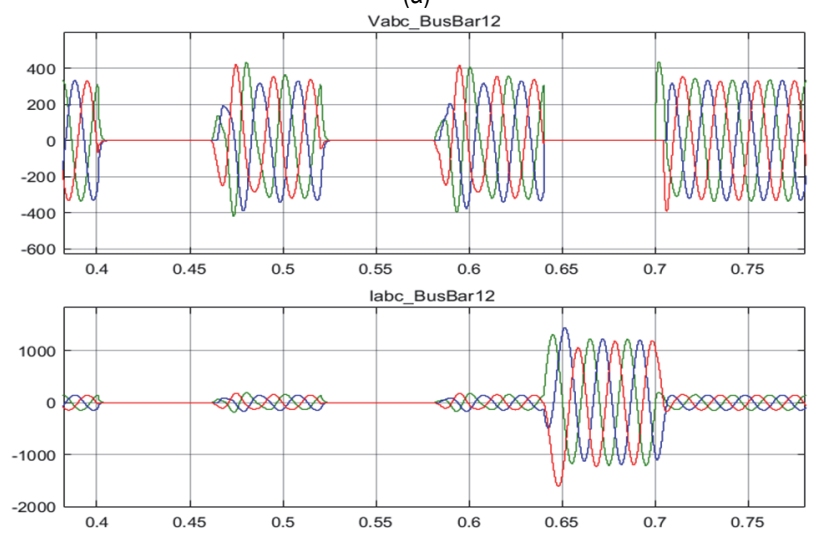

(b)

Figure 9 a) BusBar7 voltage and current after using the RSFCL under 3 faults (transmission, distribution and costumer) and b) BusBar12 voltage and current after using the RSFCL under 3 faults (transmission, distribution and costumer)

Fig. 9a illustrates the BusBar7 voltage and current after using the RSFCL under 3 faults (transmission, distribution and costumer). The BusBar7 is the closest busbar of the transmission line and the change of the voltage-current behaviour is acquired. It is the worst scenario which must be solved. Nevertheless, it seems that the fault current in BusBar7 cannot be ignored due to the overcurrent problem. The short circuit problem has been eliminated using the RSFCL and the fault current has been achieved $71.41 \%$ better. Although the energy consumption of the BusBar12 is less than others, the overcurrent problem is a serious problem to solve. It is seen that there is an improvement in the distribution line and transmission line thanks to the influence of the RSFCL. Fig. 9b shows the most affected customer line by all the faults.

Table 3 Change in fault current and Inrush Current Value Change

\begin{tabular}{|c|c|c|}
\hline Busbar Name & $\begin{array}{c}\text { Change in fault } \\
\text { current \% } \\
\text { (percentage } \\
\text { relative error) }\end{array}$ & $\begin{array}{c}\text { Average current changes } \\
\text { (Ampere) } \\
\text { (R/S/T) }\end{array}$ \\
\hline MainBusBar & $4.10 \%$ & $10.0785 / 23.0520 / 1.1519$ \\
\hline BusBar1 & $82 \%$ & $2732 / 2826 / 11436$ \\
\hline BusBar2 & $4.67 \%$ & $-371.8477 /-160.8698 / 87.4737$ \\
\hline BusBar3 & $4 \%$ & $-303.7200 /-221.7387 / 61.8292$ \\
\hline BusBar4 & $6.97 \%$ & $909.5 / 483.9 / 5826.8$ \\
\hline BusBar5 & $1.64 \%$ & $655.2 / 161.6 / 6234.7$ \\
\hline BusBar6 & $-0.32 \%$ & $78.1360 / 186.6717 / 122.1428$ \\
\hline BusBar7 & $71.41 \%$ & $4.7942 / 3.6682 /-3.2847$ \\
\hline BusBar8 & $0.73 \%$ & $8.8409 / 16.6048 / 1.0917$ \\
\hline BusBar9 & $6.85 \%$ & $92.5008 / 162.1920 / 15.1295$ \\
\hline BusBar10 & $1.57 \%$ & $9.6134 / 17.4987 / 0.5656$ \\
\hline BusBar11 & $11.62 \%$ & $86.7634 / 150.1302 / 0.2678$ \\
\hline BusBar12 & $82.78 \%$ & $240.0594 / 724.9533 /-776.4881$ \\
\hline
\end{tabular}

Another advantage of using the RSFCL is that After the RSFCL is used, the ripples of voltage-current have decreased. In the case of using the RSFCL, the real city distributed grid can provide less overcurrent problem and the nominal current is drawn from the transformer feeding the system. Providing the feeding desired current of the customer line emphasizes the advantage of using the RSFCL. Eliminated is short circuit failure for the BusBar12 too. Furthermore, an improvement in the fault current is provided as $82.78 \%$. All busbar results, which consist of change in fault current and inrush current value change, are given in Tab. 3. The purpose of the table is to give what improvement is achieved when using the RSFCL by finding the overcurrent in all busbars. 12 busbar results as the change in fault current and current ripple changes are given. According to results, it is seen that the nodes of the RSFCL places are also the places of the maximum current flow points in every busbar. MainBusBar, known as the distribution busbar for other busbars, has improvements which are: a change in fault current (percentage relative error) is $4.10 \%$ and in current ripple changes $(\mathrm{R} / \mathrm{S} / \mathrm{T})$ is $10.0785 / 23.0520 / 1.1519 \mathrm{~A}$ respectively.

These improvements are the following: a change in fault current (percentage relative error) is $82 \%$ and in current ripple changes $(\mathrm{R} / \mathrm{S} / \mathrm{T})$ is $2732 / 2826 / 11436 \mathrm{~A}$ respectively for BusBar1. For BusBar2, 4.67\% change in fault current and -371.8477/-160.8698/87.4737 A current ripple changes are found. Obtained change in fault current is $4 \%$ and current ripple changes are $-303.7200 /-221.7387 / 61.8292$ A for BusBar 3. BusBar4 has $6.97 \%$ change in fault current and 909.5/483.9/5826.8 $\mathrm{A}$ in current ripple changes. BusBar5 has $1.64 \%$ change in fault current and 655.2/161.6/6234.7 $\mathrm{A}$ in current ripple changes. BusBar6 has $-0.32 \%$ change in fault current and $78.1360 / 186.6717 / 122.1428$ A current ripple changes. BusBar7 has $71.41 \%$ change in fault current and 4.7942/3.6682/-3.2847 A current ripple changes. BusBar8 has $0.73 \%$ change in fault current and 
8.8409/16.6048/1.0917A current ripple changes. BusBar9 has $6.85 \%$ change in fault current and 92.5008/162.1920/15.1295 A current ripple changes. BusBar10 has $1.57 \%$ change in fault current and 9.6134/17.4987/0.5656 A current ripple changes. BusBar11 has $11.62 \%$ change in fault current and $86.7634 / 150.1302 / 0.2678$ A current ripple changes. And lastly, BusBar12 has $82.78 \%$ change in fault current and 240.0594/724.9533/-776.4881 A current ripple changes. Also, these result values are average ripple fault current values. In example, BusBar7 has $71.41 \%$ change in fault current and it is 4.7942/3.6682/-3.2847 R/S/T respectively. In Fig. 9a, the current can be seen over $200 \mathrm{~A}$, but average values are abnormal values. They are deviation in normal current. Normally, it should be $0 / 0 / 0 \mathrm{R} / \mathrm{S} / \mathrm{T}$ if faults do not occur. When the results are examined, especially changes in fault current of BusBar1 and BusBar12 are significantly improved. In addition, current ripple changes of BusBarl, BusBar4 and BusBar12 are remarkably decreased. Although these are outstanding improvements, change in fault current of BusBar6, BusBar8 and BusBar10 has not changed much. However, current ripple changes of BusBar7 have been little optimized. Obtained nodes by the multi-objective genetic algorithm are the best points to place the RSFCL. The SFCL is placed at the point where the maximum current is drawn because of deterioration in the busbars. The RSFCL, which should be set up to the real distributed city grid in this way, can prevent the system from suffering major damages in the event of major failures.

\section{CONCLUSION}

In this paper, power flow and short circuit phenomena of a modelled real energy transmission grid using Matlab/Simulink are investigated. As a result of the power flow, current and voltage changes are obtained in the transmission grid, power transmission lines and loads in the transmission grid. Short circuit currents, especially in interconnection and many transmission lines, cause very considerable problems in the systems that cause damage that cannot be repaired especially in the transformer. In order to prevent the problem, the RSFCL element is used in this study. However, RSFCLs must be connected at the best points for using less fault current limiters to achieve maximum efficiency. The RSFCL, which should be set up to the real distributed city grid in this way, can prevent the system from suffering major damages in the event of major failures.

The approach proposes the use of RSFCL elements at decided nodes of the grid in the distribution lines based on the multi-objective genetic algorithm results of the analysis of the RSLFC mathematical model for electricity generation, distribution and consumption. In addition, short circuit faults applied to the grid in literature studies are applied at different points at the same time. This results in the grid being unable to be analysed correctly because there can be many faults in a distributed grid. So, three short circuit faults have been applied in short time intervals to see the damage better. Thus, changes are investigated more objectively for each busbar and with each RSFCL element. As a result of the study, applied short circuit faults in far point affected the entire grid to a large extent for the transmission, the distribution line and the customer line. But using the RSFCL, the negative effects of the faults have been notably solved. When the results are compared to the literature, it is precisely shown that the short circuit fault currents are significantly reduced when using RSFCL at the best nodes. Thus, the importance of SFCL in the real distributed city grids has been especially proved once more.

\section{REFERENCES}

[1] Weller, R. A., Campbell, A. M., Coombs, T. A., Cardwell, D. A., Storey R. J. \& Hancox, J. (1999). Computer modelling of superconducting film type fault current limiters. IEEE Transactions on Applied Superconductivity, 9(2), 13771380. https://doi.org/10.1109/77.783559

[2] Fedasyuk, D. \& Serdyuk, P. (2006). Mathematical model of thermo electrical processes in resistive superconducting fault current limiter. International Conference Modern Problems of Radio Engineering, Telecommunications, and Computer Science, 77-80. https://doi.org/10.1109/TCSET.2006.4404450

[3] Yilmaz, E. N., Aksoz, A., \& Saygın, A. (2018). Design of an off-grid model of micro-smart grid connection of an asynchronous motor fed with LUO converter. Electrical Engineering, 100(4), 2659-2666. https://doi.org/10.1007/s00202-018-0734-4

[4] Can, E., (2019). Fault determination and analysis of complex switching structure at multilevel inverter. Tehnički vjesnik, 26(2), 398-404. https://doi.org/10.17559/TV-20180417194701

[5] Baldan, C. A., Shigue, C. Y., \& Ruppert Filho, E., (2015). Electrical and Thermal Characterization of YBCO Coated Conductors for Resistive Fault Current Limiter Applications. IEEE Transactions on Applied Superconductivity, 25(3), 14. https://doi.org/10.1109/TASC.2015.2390622

[6] Emhemed, A. S., Tumilty, R. M., Singh, N. K., Burt, G. M., \& McDonald, J. R. (2010). Analysis of Transient Stability Enhancement of LV-Connected Induction Microgenerators by Using Resistive-Type Fault Current Limiters. IEEE Transactions on Power Systems, 25(2), 885-893. https://doi.org/10.1109/TPWRS.2009.2034859

[7] Bock, J., Hobl, A., Schramm, J., Krämer, S. \& Jänke, C. (2015). Resistive Superconducting Fault Current Limiters are Becoming a Mature Technology. IEEE Transactions on Applied Superconductivity, 25(3), 1-4. https://doi.org/10.1109/TASC.2014.2364916

[8] Can, E. \& Sayan, H. H. (2017). The increasing harmonic effects of SSPWM multilevel inverter controlling load currents investigated on modulation index. Tehnički vjesnik, 24(2), 397-404. https://doi.org/10.17559/TV-20151020134629

[9] Hayakawa, N., Mimbu, M., Kojima, H., Isojima, S., \& Kuwata, M. (2019). Dynamic breakdown characteristics of pancake coil model for resistive-type superconducting fault current limiters. IEEE Transactions on Applied Superconductivity, 29(5), 1-6. https://doi.org/10.1109/TASC.2019.2909200

[10] Lim, S. \& Lim, S. (2019). Analysis on coordination of overcurrent relay using voltage component in a power distribution system with a SFCL. IEEE Transactions on Applied Superconductivity, 29(5), 1-5. https://doi.org/10.1109/TASC.2019.2904668

[11] Fedasyuk, D., Serdyuk, P., \& Semchyshyn, Y. (2008). Resistive superconducting fault current limiter simulation and design. 15th International Conference on Mixed Design of Integrated Circuits and Systems, 349-353.

[12] Morandi, A. (2013). State of the art of superconducting fault current limiters and their application to the electric power system. Physica C: Superconductivity, 484, 242-247. https://doi.org/10.1016/j.physc.2012.03.004 
[13] Jain, A., Dubey, V. K., Jawale, G., Mangalvedekar, H. A., \& Kanakgiri, K. (2016). Limiting fault current in a power system grid by SFCL: A step input approach. 6th International Conference on Power Systems (ICPS), 1-5. https://doi.org/10.1109/ICPES.2016.7584095

[14] Wang, Z., Wang, S., Qiu, J., Gong, W., \& Zhang, J. Induced voltage analysis of superconducting fault current limiter. The International Journal for Computation and Mathematics in Electrical and Electronic Engineering, 33(1/2), 38-46. https://doi.org/10.1108/COMPEL-11-2012-0342

[15] Moon, W.S., Won, J. N., Huh, J. S., \& Kim, J. C. (2013). A study on the application of a superconducting fault current limiter for energy storage protection in a power distribution system. IEEE Transactions on Applied Superconductivity, 23(3), 5603404-5603404. https://doi.org/10.1109/TASC.2013.2238594

[16] Yadav, S., Mandal, R. K., \& Choudhary, G. K. (2014). Determination of appropriate location of superconducting fault current limiter in the smart grid. International Conference on Smart Electric Grid (ISEG), 1-9. https://doi.org/10.1109/ISEG.2014.7005580

[17] Saygin, A. \& Ahmet, A. (2017). Design optimization for minimizing cogging torque in Axial Flux Permanent Magnet machines. OPTIM \& ACEMP, 324-329. https://doi.org/10.1109/OPTIM.2017.7974991

[18] Alaraifi, S. \& El Moursi, M. S. (2017). Design considerations of superconducting fault current limiters for power system stability enhancement. IET Generation, Transmission \& Distribution, 11(9), 2155-2163. https://doi.org/10.1049/iet-gtd.2016.0549

[19] Vilhena, N., Murta-Pina, J., Pronto, A., \& Álvarez, A. (2018). A design methodology for the optimization of threephase SFCL of saturated cores type. IEEE Transactions on Applied Superconductivity, 28(4), 1-5. https://doi.org/10.1109/TASC.2018.2806001

\section{Contact information:}

Ahmet AKSOZ, Assistant Professor, PhD

(Corresponding author)

Sivas Cumhuriyet University,

Department of Energy Science and Technology,

Sivas Cumhuriyet University, 58340, Merkez/Sivas, Turkey

E-mail: aaksoz@cumhuriyet.edu.tr 